\title{
The reign of the natriuretic peptides in patients with heart failure continues
}

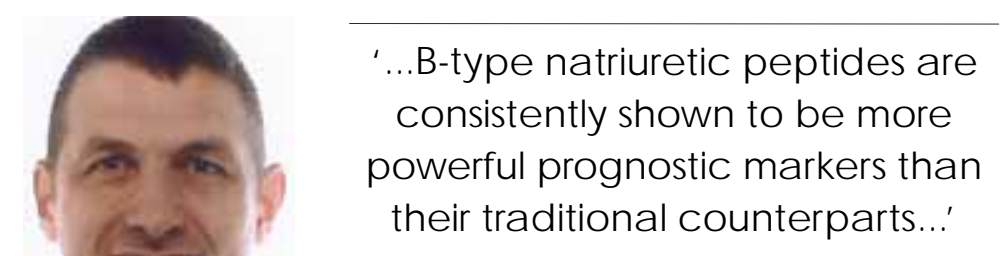

It was encouraging to see that there were several sessions dedicated to biomarkers at the annual meeting of the European Society of Cardiology (ESC) in September 2008, particularly in relation to patients with heart failure. H owever, the large number of novel markers currently being investigated in this field only highlights our rudimentary understanding of the complex interaction of the neurohormonal systems involved. Still, the diagnostic and prognostic power of some of these biomarkers is without question, and despite this (like many successes in clinical studies) they are slow to be adopted into standard clinical practice.

This is particularly true of the B-type natriuretic peptides (BN Ps) [1]. Discovered 20 years ago [2], the BN Ps are now well known to be increased in both asymptomatic and symptomatic left ventricular systolic dysfunction (LVSD ), rising in proportion to the severity of chronic heart failure [3-5]. BN P can accurately detect LVSD in the general population [6], but it is particularly useful as a 'rule-out' test owing to its high negative predictive value. As such, the BN Ps are now recommended by the ESC [7] and American College of Cardiology/American $\mathrm{H}$ eart Association [8] for the diagnosis of both acute and chronic heart failure.

The return of atrial natriuretic peptide? Although atrial natriuretic peptide (ANP) was discovered prior to BN Ps, its diagnostic potential in chronic heart failure (for both its $\mathrm{C}$ - and $\mathrm{N}$-terminal fragment) was inferior to BN Ps, and assays were not developed further. H owever, recent evidence suggests that an assay targeting the more stable region of mid-regional pro-AN $P$ (M R-proAN P) is just as accurate as BN Ps in diagnosing heart failure. In a retrospective study by Gegenhuber etal. involving over 250 patients presenting to the emergency room with dyspnea,
M R-proAN P concentrations were found to be significantly higher in patients with dyspnea secondary to acute heart failure than for other causes (338 pmol/l vs $98 \mathrm{pmol} / \mathrm{l} ; \mathrm{p}<0.001$ ) [9]. In another study by von $\mathrm{H}$ aehling et al., $M R$-proAN $P$ was found to be an independent predictor of mortality in patients with chronic heart failure [10].

The Biomarkers in the Assessment of Congestive $\mathrm{H}$ eart Failure (BACH) study was, therefore, a timely study [11]. Presented at the ESC annual meeting by $\mathrm{D} r$ Alan $\mathrm{M}$ aisel, it is a large prospective trial involving 1600 patients across three continents and is currently the largest natriuretic peptide diagnostic study in acute heart failure. M R-proAN P was compared with $\mathrm{BNP}$ and $\mathrm{N}$-terminal pro-BNP (NT-proBNP) in patients presenting to the emergency room with dyspnea. M R-proAN P was found to be as useful as (i.e., not inferior to) BNP and NT -proBN $P$ in the diagnosis of acute heart failure upon receiver operating characteristic (ROC) analysis (area under the curve $=0.904,0.904$ and 0.890 , respectively). The secondary end point was also reached in that MR-proAN $P$ added diagnostic power to that of BN Ps in the logistic regression analysis, particularly in the gray zone where BN Ps can have some problems, namely in those with renal dysfunction, obesity, the elderly and those with edema.

The findings of the BACH trial are important and they continue the theme of a multimarker approach to the diagnosis of heart failure being superior to just using one. H owever, some questions remain to be answered as a result of this study. Of particular clinical relevance, what would be the additional cost of adding MR-proANP to BNP/NT-proBNP evaluation in the emergency room? Would the cost justify these modest gains in diagnostic accuracy? This will bechallenging to prove in a study conducted in many different healthcare settings. This is particularly true, as we now have convincing evidence from three randomized studies of BN P/N T -proBN P in the diagnosis of heart failure in the emergency room, demonstrating that such an approach reduces costs, improves length of stay and may lower readmission rates. The 
challenge is now to show this for M R-proAN $\mathrm{P}$, although the results of the aforementioned three studies suggest that there may be a role for $M R$-proAN $P$ analysis in the future.

\section{Prognosis}

Presently, the role of the natriuretic peptides in prognostication outwith clinical studies is less clear. BN Ps have been shown to be powerful prognostic markers in patients with acute [12] and chronic [13] heart failure, acute coronary syndromes [14], pulmonary emboli [15], as well as in the general population [4]. H owever, it is in the risk stratification of patients with heart failure syndromes that the BN Ps have had the most interest.

'B-type natriuretic peptides should now be used routinely in clinical practice, partic ularly ... in heart failure.'

There are, at our last count, over 100 clinical, hemodynamic and neurohormonal markers of prognosis in patients with heart failure. Unfortunately, these variables vary in their success at predicting outcome owing to the heterogeneous nature of heart failure together with the availability and reproducibility of investigatory tools. However, BN Ps, are consistently shown to be more powerful prognostic markers than their traditional counterparts $[13,16,17]$ and, although they have become the benchmark against which novel markers are now compared, further studies need to be performed to see how they fit in clinically.

\section{Treatment monitoring}

Following on from the original work of Troughton et al. [18], where titration of therapy guided by N T-proBN P concentration appeared to be superior to current best practice and, more recently, Systolic H eart Failure Treatment Supported by BNP (STARS-BNP) [19], where a BN P-guided strategy reduced the risk of $\mathrm{CHF}$ related death or hospital stay for $\mathrm{CHF}$, the Trial of Intensified Versus Standard M edical Therapy in Elderly patients with Congestive $\mathrm{H}$ eart Failure (TIME-CHF) study was presented at a hotline session of the ESC annual meeting [20]. Involving nearly 500 patients over the age of 60 years (average age 77 years), TIME-CHF revealed that intensified, BN P-guided therapy was no more effective than a standard, symptom-guided approach in elderly heart-failure patients aged 75 years or over in reducing the number of deaths and all-cause hospitalizations. This was not true for the younger cohort in the study (60-74 years), and this may partly be explained by the greater number of co-morbidities and reduced applicability of treatment recommendations in the very elderly.

The next treatment-monitoring trial to be formally reported is BN P-Assisted Treatment To Lessen Serial Cardiovascular Readmissions and D eath (BATTLE-SCARRED) [21]. Provisional results were presented by $M$ ark Richards at the $\mathrm{H}$ eart Failure M eeting of the ESC earlier this year [22], and they appear to corroborate the results of TIM E-CH F. Patients were randomized to have therapy guided by NT-proBN P or to standard care. It appeared that those patients aged less than 70 years randomized to the N T-proBN P-guided group had a reduction in morbidity and mortality, but this was not seen in those over the age of 70 years. We believe that the formal results are due to be published imminently, and we await them with great interest.

\section{Where to now?}

With the current body of evidence, BN Ps should now be used routinely in clinical practice, particularly in areas where that evidence is greatest - in heart failure. Further research needs to be undertaken to clarify whether they can be used to identify patients in greatest need of advanced heart-failure therapies, such as implantable cardioverter defibrillators, cardiac resynchronization therapy or cardiac transplantation. For certain, the BN Ps are here to stay and with greater experience will come greater utility.

Financial \& competing interests disclosure The authors have no relevant affiliations or financial involve ment with any organization or entity with a financial interest in or financial conflict with the subject matter or materialsdis cussed in the manuscript. This includes employment, consultancies honoraria, stock ownership or options, expert testimony, grants or patents received or pending, or royalties

No writing assistance was utilized in the production of this manuscript.

\section{Bibliography}

1. Gardner RS, Chong KS, M CD onagh TA: $B$-type natriuretic peptides in heart failure. Biomark. M ed. 1(2), 243-250 (2007).
2. Sudoh $T$, Kangawa $K$, M inamino $N$, $\mathrm{M}$ atsuo $\mathrm{H}$ : A new natriuretic peptide in porcine brain. $\mathrm{N}$ ature 332(6159), 78-81 (1988).
3. Lerman A, Gibbons RJ, Rodeheffer RJ et al.: Circulating $\mathrm{N}$-terminal atrial natriuretic peptide as a marker for symptomless left-ventricular dysfunction. Lancet 341, 1105-1109 (1993). 


\section{The reign of the natriuretic peptides in patients with heart failure continues - ED IT O RIAL}

4. MCD onagh TA, Cunningham AD, M orrison CE et al.: Left ventricular dysfunction, natriuretic peptides, and mortality in an urban population. H eart 86(1), 21-26 (2001)

5. Tsutamoto $T$, Wada $A, M$ aeda $K$ et al.: Plasma brain natriuretic peptide level as a biochemical marker of morbidity and mortality in patients with asymptomatic or minimally symptomatic left ventricular dysfunction. Comparison with plasma angiotensin II and endothelin-1. Eur. H eart J. 20(24), 1799-1807 (1999).

6. M CD onagh TA, Robb SD, M urdoch D R et al.: Biochemical detection of leftventricular systolic dysfunction. Lancet 351(9095), 9-13 (1998).

7. Dickstein K, Cohen-Solal A, Filippatos G et al.: ESC Guidelines for the D iagnosis and Treatment of Acute and $\mathrm{C}$ hronic $\mathrm{H}$ eart Failure. Eur. H eart J. 29, 2388-2442 (2008).

8. Hunt SA, Abraham WT, Chin M H et al.: ACC/AH A 2005 G uideline U pdate for the $D$ iagnosis and $M$ anagement of $C$ hronic $\mathrm{H}$ eart Failure in the Adult: a report of the American College of $\mathrm{C}$ ardiology/American $\mathrm{H}$ eart Association Task Force on Practice Guidelines. Circulation 112(12), e154-e235 (2005).

9. Gegenhuber A, Struck J, Poelz W et al.: $M$ idregional pro-A-type natriuretic peptide measurements for diagnosis of acute destabilized heart failure in short-of-breath patients: comparison with B-type natriuretic peptide (BN $P$ ) and amino-terminal proBN P. Clin. Chem. 52(5), 827-831 (2006).
10. von $\mathrm{H}$ aehling $\mathrm{S}$, Jankowska $\mathrm{EA}$, M orgenthaler $\mathrm{NG}$ et al.: Comparison of midregional pro-atrial natriuretic peptide with $\mathrm{N}$-terminal pro-B-type natriuretic peptide in predicting survival in patients with chronic heart failure. J. Am. Coll. Cardiol. 50(20), 1973-1980 (2007).

11. M aisel $A$ : The BACH (Biomarkers in the Assessment of Congestive $\mathrm{H}$ eart Failure) study. European Society of Cardi ology Annual Congress. M unich, Germany, 30 August- 3 September 2008.

12. Cheng V, Kazanagra R, Garcia A et al.: A rapid bedside test for $B$-type peptide predicts treatment outcomes in patients admitted for decompensated heart failure: a pilot study. J. Am. Coll. Cardiol. 37(2), 386-391 (2001).

13. Gardner RS, 0 zalp F, M urday AJ, Robb SD , $M C D$ onagh TA: $N$-terminal pro-brain natriuretic peptide. A new gold standard in predicting mortality in patients with advanced heart failure. Eur. Heart J. 24(19), 1735-1743 (2003).

14. de Lemos JA, M orrow DA, Bentley JH et al.: The prognostic value of $B$-type natriuretic peptide in patients with acute coronary syndromes. N . Engl. J. M ed. 345(14), 1014-1021 (2001).

15. ten Wolde M, Tulevski II, M ulder JW et al.: Brain natriuretic peptide as a predictor of adverse outcome in patients with pulmonary embolism. Circulation 107(16), 2082-2084 (2003).

16. Gardner RS, Chong V, M orton I, $M C D$ onagh TA: $\mathrm{N}$-terminal brain natriuretic peptide is a more powerful predictor of mortality than endothelin-1, adrenomedullin and tumour necrosis factor- $\alpha$ in patients referred for consideration of cardiac transplantation. Eur. J. H eart Fail. 7(2), 253-260 (2005).

17. G ardner RS, $H$ enderson $G, M C D$ onagh $T A$ : The prognostic use of right heart catheterization data in patients with advanced heart failure: how relevant are invasive procedures in the risk stratification of advanced heart failure in the era of neurohormones? J. H eart Lung Transplant. 24(3), 303-309 (2005).

18. Troughton RW, Frampton CM, Yandle TG, Espiner EA, N icholls M G, Richards AM : Treatment of heart failure guided by plasma aminoterminal brain natriuretic peptide (N -BN P) concentrations. Lancet 355(9210), 1126-1130 (2000).

19. Jourdain $P$, Jondeau $G$, Funck $F$ et al.: Plasma brain natriuretic peptide-guided therapy to improve outcome in heart failure: the STARS-BN P M ulticenter Study. J. Am. Coll. Cardiol. 49(16), 1733-1739 (2007).

20. TIM E-CH F (Trial of Intensified versus standard M edical therapy in Elderly patients with Congestive $\mathrm{H}$ eart Failure) study. European Society of $\mathrm{C}$ ardiology Annual Congress. M unich, G ermany, 30 August-3 September 2008.

21. Lainchbury JG, Troughton RW, Frampton CM et al.: N T proBN P-guided drug treatment for chronic heart failure: design and methods in the 'BAT TLESCARRED' trial. Eur. J. H eart Fail. 8(5), 532-538 (2006).

22. Richards AM : BAT TLESCARRED Presented at: European Society of Cardiology: $H$ eart Failure Congress. M unich, G ermany, 30 August- 3 September 2008. 